\title{
Universiteit
}

Leiden

The Netherlands

\section{No matter - how? dealing with matter-less stressors in LCA of wind energy systems}

Cucurachi, S.; Giesen, C.C. van der; Heijungs, R.; Snoo, G.R. de

\section{Citation}

Cucurachi, S., Giesen, C. C. van der, Heijungs, R., \& Snoo, G. R. de. (2016). No matter how?: dealing with matter-less stressors in LCA of wind energy systems. Journal of Industrial Ecology, 21(1), 70-81. doi:10.1111/jiec.12416

Version: Publisher's Version

License: $\quad$ Licensed under Article 25fa Copyright Act/Law (Amendment Taverne)

Downloaded from: https://hdl.handle.net/1887/3199544

Note: To cite this publication please use the final published version (if applicable). 


\title{
No Matter - How? \\ Dealing with Matter-less Stressors in LCA of Wind Energy Systems
}

\author{
Stefano Cucurachi, Coen C. van der Giesen, Reinout Heijungs, and Geert R. de Snoo
}

\author{
Keywords: \\ life cycle assessment (LCA) \\ life cycle impact assessment ( $\mathrm{LCIA}$ ) \\ life cycle inventory $(\mathrm{LCl})$ \\ matter-less stressors \\ noise impacts \\ wind turbine
}

: 21

Supporting information is available on the JIE Web site
I

\begin{abstract}
Summary
The portfolio of impacts that are quantified in life cycle assessment (LCA) has grown to include rather different stressors than those that were the focus of early LCAs. Some of the newest life cycle impact assessment (LCIA) models are still in an early phase of development and have not yet been included in any LCA study. This is the case for sound emissions and noise impacts, which have been only recently modeled. Sound emissions are matter-less, time dependent, and bound to the physical properties of waves. The way sound emissions and the relative noise impacts are modeled in LCA can show how new or existing matterless impacts can be addressed. In this study, we analyze, through the example of sound emissions, the specific features of a matter-less impact that does not stem from the use of a kilogram of matter, nor is related to the emission of a kilogram of matter. We take as a case study the production of energy by means of wind turbines, contradicting the commonly held assumption that windmills have no emissions during use. We show how to account for sound emissions in the life cycle inventory phase of the life cycle of a wind turbine and then calculate the relative impacts using a noise LCIA model.
\end{abstract}

\section{Introduction}

When conducting a life cycle assessment (LCA) activities which are related to and affected by a functional unit should be included in the life cycle inventory (LCI), and then in the life cycle impact assessment (LCIA) (Rugani et al. 2012). Originally, only impacts (and activities) related to physical extractions and emissions, thus to material inputs and outputs from a product system, were modeled in LCA (Udo de Haes et al. 2004). During the last decade, however, researchers expanded the boundaries of LCA, also allowing other impacts to be included in the cases in which the relationship to a functional unit is not mediated by the extraction/emission pattern.

A number of stressors (i.e., pressures on the environment) that are included or recommended for inclusion in the LCA framework are not substance induced, nor directly related to emissions and physical exchanges of matter with the environment. Stressors such as noise or light pollution are forms of matter-less emissions, which cannot be directly accounted for by, for example, respiration or food consumption. In particular, we define here as matter-less stressors those that are not related to a release of a certain quantity of matter (e.g., $\mathrm{kg}$ of carbon dioxide). Moreover, the damage such stressors determine involves a mix of physio- and psychological conditions of exposure that make their analysis rather situation specific. The process of modeling such matter-less impacts has not developed as fast as that of the traditional substance-induced impact categories. The reasons behind this slower pace of development reflects the difficulty of modeling the stressors in a way that accommodates the computational structure of LCA (see Heijungs and Suh 2002) or the level of knowledge of the mechanisms that determine their impacts (see Cucurachi et al. 2012).

Address correspondence to: Stefano Cucurachi, Bren School of Environmental Science and Management, 2400A, University of California Santa Barbara, Santa Barbara, CA 93106-5131, USA. Email: scucurachi@bren.ucsb.edu 
Examples of matter-less stressors, for which methodological attempts have already been made, include land use (Milá i Canals and de Baan 2015; de Baan et al. 2013; Brandão and Milá i Canals 2013), noise (Cucurachi et al. 2012; Cucurachi and Heijungs 2014), and thermal pollution (Verones et al. 2010). In other cases, matter-less impacts have been related to the exchange of a certain quantity of matter between the ecosphere and the biosphere. This is the case of the introduction of exotic species by means of freight transport of goods, as described by Hanafiah and colleagues (2013), and the impacts of ionizing radiation resulting from the release of radioactive substances (Frischknecht et al. 2000).

The case of noise (see Cucurachi et al. 2012; Cucurachi and Heijungs 2014) is used in this study as an exemplar model type to illustrate how to deal with matter-less emissions and impacts. We analyze the case of wind turbines to test the applicability of a noise-impact method and to further understand the importance of the analysis of emerging impacts in the field of LCA. Whereas existing LCA studies show that upstream processes in the life cycle contribute the most to emissions and impacts (see, e.g., Dolan and Heath 2012), we show that it is now possible to quantify the noise impacts of wind turbines during their operation and during other phases of their life cycle phases in which sound is emitted. The operation of this type of system produces emissions that are not related to a release of matter, but do have, just like, for example, toxic emissions, an impact on the population living in the area surrounding a turbine.

The remainder of the article is organized as follows. We first clarify the specificities of matter-less stressors for the LCI and LCIA phases of LCA. We then quantify noise emissions and show the impact of noise for configurations of wind turbines that vary by physical (e.g., height of the hub) and local conditions (e.g., wind speed). The article closes with concluding remarks regarding the importance of noise in the life cycle of wind turbines.

\section{The Input, the Output for Matter-less Stressors}

\section{The Inventory Analysis and the Relationship to a Functional Unit}

In LCA, the study of a life cycle of a product system scales all inputs to the functional unit that best represent the goal and scope of the system under analysis. The usual way to proceed in the LCI phase is to detail the conversion of inputs (e.g., products, waste, and resources) into outputs (e.g., products, waste, and residuals to the environment; Curran [2012]). For some unit processes and/or stressors, the relationship between inputs and outputs is not immediately obvious. We show that, in some cases, before an emission can be recorded in the inventory table, it is necessary to define a further emission-specific conversion factor that allows for similar emissions across the life cycle to be compared. In general, the LCI phase deals with the represen- tation of the relationship between flows of inputs and outputs and unit processes. Using a simple representation, one could describe a unit process as in figure 1 .

To express all resource inputs and emissions per unit of product following the notation introduced in figure 1 , the process must be multiplied by a scaling factor $1 / D$. Note that this scaling factor has the dimension of time. It can be interpreted as the time it takes for the unit process operating at full production volume to produce 1 unit of product (Heijungs and Suh 2002). The resource input then becomes $B \times \frac{1}{D}$ and the emission $E \times \frac{1}{D}$. These results are in $\mathrm{kg}$. For the case of $\mathrm{C}$, and considering, as in the example, a land-use input, we would proceed by calculating $\mathrm{C} \times \frac{1}{D}$, thus with the dimension square meters $\times$ years (yr) (Brandão and Milá i Canals 2013). So far, this works fine, because products, mass, and area are aggregable quantities. Let us consider a matter-less output, see, for example, $\mathrm{F}$ in figure 1 . If we consider the example of sound, the output is typically expressed in decibels $(\mathrm{dB})$, which, in contrast, may not be aggregated by simple addition because the unit is logarithmic. As a result, $\mathrm{dB}$ is inconvenient for the purely linear aggregations and additions that are common in LCA. It must be first converted into an energy unit (the joule) to be aggregable. The amount of sound thus becomes $g(F) \times \frac{1}{D}$, where $g(F)$ is a transformation function (Cucurachi et al. 2012; Cucurachi and Heijungs 2014). This result is in watts $(\mathrm{W}) \times \mathrm{yr}$, which corresponds to joules $(\mathrm{J})$.

The crucial element of this whole discussion is in the function $g$, which transforms a nonmaterial elementary flow (i.e., an input or output flow to a unit process or product system originating or ending up in the environmental system) that is nonaggregable into an aggregable one. The transformation function $g$ is defined according to the local conditions of the system under study and to the specific properties (i.e., physical or otherwise) of the matter-less emission under consideration. Several local parameters (e.g., production rate of a system, speed of a vehicle) may be needed according to the type of matter-less emission under consideration.

\section{Life Cycle Impact Assessment}

Once the LCI phase is concluded, if enough information has been stored in the LCI, a suitable impact assessment model for a matter-less stressor thus would have to take into account a series of emission-specific properties and solve all potential nonlinearities. Nonlinear cause-effect curves are common also for other material impact pathways. The impact score for that specific impact category under consideration would be obtained simply by multiplying the characterization factor by the related inventory item. For some matter-less impacts that are highly localized (e.g., that depend on population density or the ambient $\mathrm{pH}$ ), time specific (e.g., that depend on the time of the day or the year), or property specific (e.g., that depend on the frequency or polarization), a system of characterization factors will be needed to represent all possible conditions of fate, effect, exposure, and damage. 


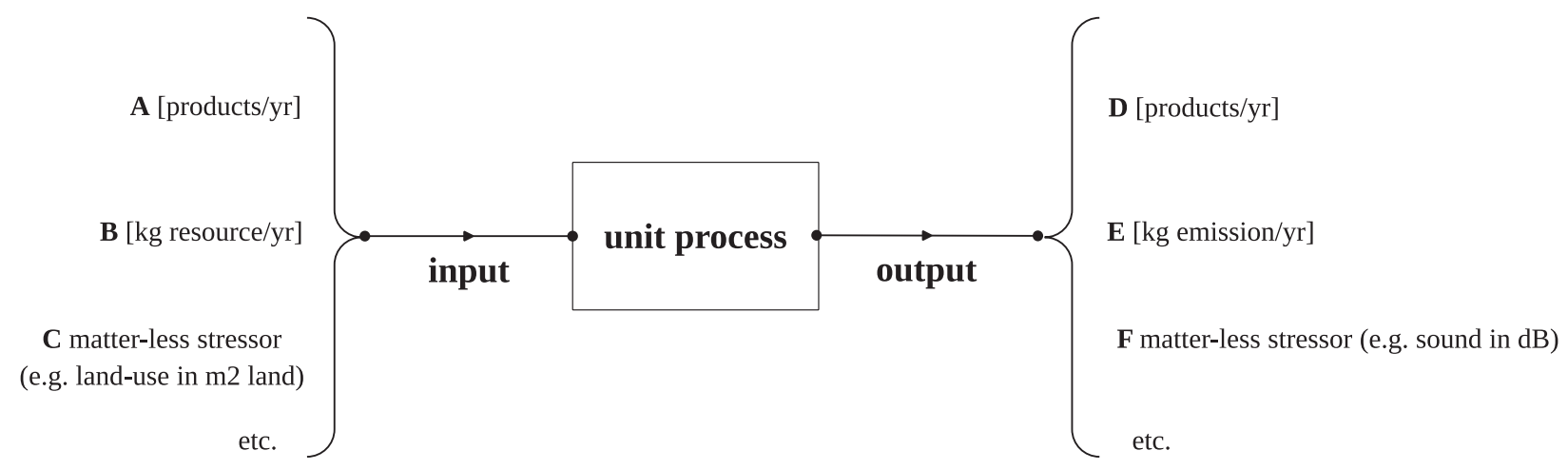

Figure I Inputs and outputs of a unit process in the LCl phase. The flows here include a time-based property, in contrast to the usual LCA practice where the flows are written as amounts ("kg", "product", and so on). LCl = life cycle inventory; kg = kilogram.

\section{The Life Cycle of a Wind Turbine}

\section{Wind Energy, Wind Turbines, and their Impacts in Life Cycle Assessment}

Wind turbines are considered a promising "sustainable" energy source for our energy supply portfolio and have become one of the most often cited sources of electricity generation to address, for example, climate-change issues (Doblinger and Soppe 2013; GWEC 2013). With the exception of direct solar heat and light, wind energy is believed to have the least adverse environmental impacts of all renewable energy technologies (Premalatha et al. 2014). Though these features of wind power are promising, the use of kinetic energy for the production of power does not come free of impacts.

Within the field of LCA, Dolan and Heath (2012) identified 240 LCA studies that have investigated the environmental impacts of electricity from on- and offshore wind farms. To our knowledge, none of these studies accounted for the impacts during the use phase of the wind turbine, apart from the impacts related to the maintenance and lubrication of components. Researchers thus assume that wind turbines do not have any direct measurable environmental impact related to their operation. However, a variety of potential environmental effects have been related to wind turbines in analyses outside of LCAs. These include noise, electromagnetic interference, visual impacts, impacts on wildlife, and, the more recently investigated, impacts on local weather and surface temperature (Boyle 2004; Walsh-Thomas et al. 2012; Zhou et al. 2012; Premalatha et al. 2014; Vautard et al. 2014).

Recent developments in LCIA (see Cucurachi et al. 2012; Cucurachi and Heijungs 2014) allow one to quantify sound emissions related to any sound-emitting source, including static sources (e.g., a wind turbine), and mobile sources (e.g., transportation means) in all life cycle stages. Noise is the most frequently identified issue related to the setting up of a wind farm (Tabassum-Abbasi 2014).

\section{Goal and Scope of the Study}

The goal of the current study is to evaluate the impacts of sound emissions from resource extraction to operation for wind turbines next to commonly measured impacts. We complement the inventory of the recent study by Caduff and colleagues (2012) with inventory data regarding the emission of sound and with the background data provided by the ecoinvent database version 2.2 (Frischknecht et al. 2005). A variety of wind turbine configurations are compared to show how prone to variability sound emissions and impacts are, depending on the local conditions under study. The LCA software CMLCA version 5.2 (Heijungs 2013) was used to model the different configurations and perform the analysis and calculations.

\section{System Definition and Relationship to the Functional Unit}

The model defined by Caduff and colleagues (2012) uses scaling and size equations to identify the relationship between a certain configuration of wind turbine and the elementary flows (e.g., materials used and assembly of a component of the generator). Basic wind power equations are used to calculate the produced electricity per year (i.e., in kilowatt-hours per year $[\mathrm{kWh} / \mathrm{yr}]$ ) at different nominal powers and similar hub heights and diameters. A functional unit of $1 \mathrm{kWh}$ was selected. In the current study, we adopt a similar system definition as in Caduff and colleagues (2012) and include in the analysis the following phases of the life cycle: resource extraction; material manufacturing and processing; production of the components; transport to the erection site; turbine maintenance and disposal; and turbine operation (see figure 2 below).

Because of lack of specific data, we excluded from the analysis the energy for the assembly of components and for the decommissioning of the wind turbine (see Caduff et al. 2012). Inventory data for resource extraction, transportation of components, material manufacturing, disposal, and land use were associated to each of the components of the wind turbine (i.e., rotor, nacelle, tower, foundation, cables, and electrobox) according to the indication of Caduff and colleagues (2012)

In this study, we selected a number of representative configurations based on the availability of sound emissions data for models of wind turbines analyzed in Caduff and colleagues (2012). Varied local conditions were defined in order 


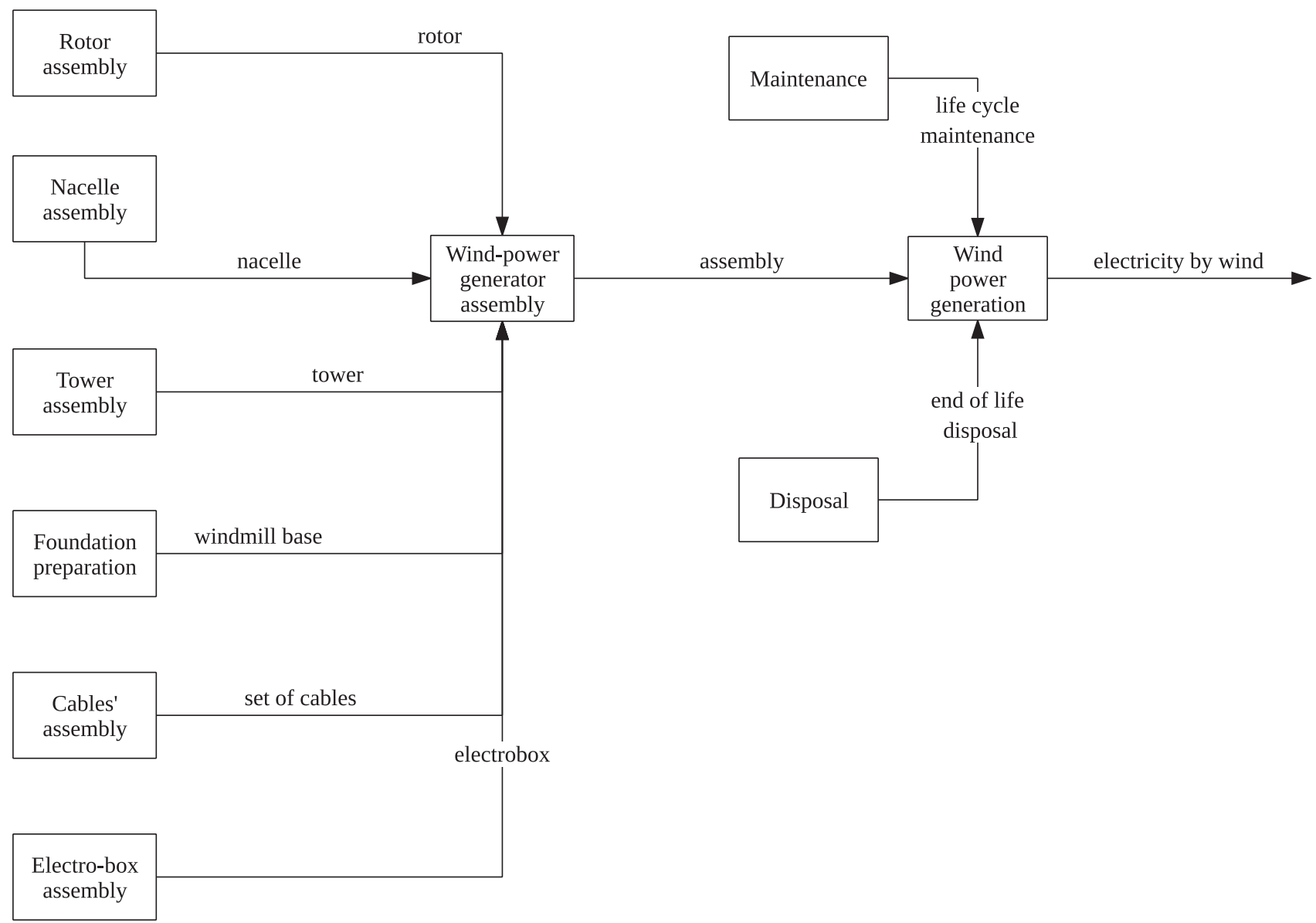

Figure 2 System flow chart: definition of elementary flows and input-output relationships. Boxes represent processes, arrows represent products.

to highlight the influence on sound emissions of different local conditions of wind speeds and revolutions per minute (RpM), also for systems with the same nominal power, but different hub heights and diameters. The defined configurations are reported in table 1 and were used to calculate the total potentially produced electricity following the engineering approach detailed in Caduff and colleagues (2012). As reported in table 1 , higher wind speeds correspond to a lower time to produce $1 \mathrm{kWh}$ of energy. We report in table 1 also the capacity factors obtained applying the calculation procedure described in Caduff and colleagues (2012). The average capacity factor for the analyzed wind turbines was $22 \%$, in line with the average European value reported by Boccard (2010) and Arvesen and Hertwich (2012) for onshore installations. Installations at lower wind speeds at hub height resulted in a lower capacity factor (see, e.g., configurations [A11] and [A38] in table 1). Further assumptions related to the physical relationships (e.g., efficiency factors and losses) between engineering parameters and the inventories were maintained.

The study by Caduff and colleagues (2012) was complemented with information related to the sound emissions of the wind turbines. We obtained sound power levels from the study by Zanetta (2008), in which experimental and extrapolated data are provided for a variety of configurations of wind turbine. The sound power level of a source is expressed in $\mathrm{dB}$ relative to a reference sound power of 1 picowatt (i.e., $10^{-12} \mathrm{~W}$ ). This quantity is commonly used to account for the logarithmic perception of sound by humans. The corresponding sound power is the amount of sound energy a source emits by converting a different kind of energy (e.g., mechanical) into sound energy, with the loudness of the sound depending on how rapidly such a conversion takes places (see Blackstock [2000] for a thorough study). For a sound source, unlike sound pressure, sound power is neither room dependent nor distance dependent. Sound power is a measure of the sound energy produced versus time, thus it has units of J per second (i.e., W). In the life cycle under study, both the mechanical and aerodynamic specifications of the turbines contribute to the sound power levels reached by the wind turbine (Pedersen and Waye 2004). As a modeling simplification, we assume a constant speed of operation of the turbines, thus no variation over time of the sound power. Later, at the LCIA phase, the time component of the emission (i.e., related to the conversion factor previously introduced) contributes to the identification of the time in which the wind turbine operates. It also accounts for the intermittency of the energy flows determined by the mechanical motion that determines 
RESEARCH AND ANALYSIS

Table I Configurations of wind turbine considered in this study

\begin{tabular}{|c|c|c|c|c|c|c|c|c|}
\hline Configuration & $\begin{array}{c}\text { Nominal Power } \\
\text { [kW] }\end{array}$ & $\begin{array}{l}\text { Wind } \\
\text { speed } \\
{[\mathrm{m} / \mathrm{s}]}\end{array}$ & Diameter [m] & $\begin{array}{c}\text { Revolutions } \\
\text { per minute } \\
{[1 / \mathrm{min}]}\end{array}$ & $\begin{array}{c}\text { Hub height } \\
\text { [m] }\end{array}$ & $\begin{array}{l}\text { Produced } \\
\text { electricity } \\
\text { per year } \\
{[\mathrm{kWh} / \mathrm{yr}]^{b}}\end{array}$ & $\begin{array}{l}\text { Capacity } \\
\text { factor }[\%]\end{array}$ & $\begin{array}{l}\text { Time for the } \\
\text { system to produce } \\
\text { functional unit } \\
\text { of } 1 \mathrm{kWh}[\mathrm{s}]\end{array}$ \\
\hline [A1] & 500 & 8 & 37 & 30 & 56 & $7.50 \mathrm{E}+05$ & 17 & 42 \\
\hline [A2] & 500 & 8 & 40.3 & 38 & 65 & $8.35 \mathrm{E}+05$ & 19 & 38 \\
\hline [A3] & 500 & 10 & 40.3 & 38 & 65 & $1.63 \mathrm{E}+06$ & 37 & 19 \\
\hline [A4] & 600 & 8 & 44 & 34.5 & 78 & $9.20 \mathrm{E}+05$ & 18 & 34 \\
\hline [A5] & 600 & 9.5 & 44 & 34.5 & 65 & $1.67 \mathrm{E}+06$ & 32 & 19 \\
\hline [A6] & 600 & 8 & 44 & 34.5 & 65 & $9.95 \mathrm{E}+05$ & 19 & 32 \\
\hline [A7] & 600 & 8 & 46 & 25 & 56 & $1.16 \mathrm{E}+06$ & 22 & 27 \\
\hline [A8] & 600 & 9.5 & 46 & 25 & 56 & $1.94 \mathrm{E}+06$ & 37 & 16 \\
\hline [A9] & 600 & 8 & 42 & 28.2 & 56 & $9.66 \mathrm{E}+05$ & 18 & 33 \\
\hline [A10] & 600 & 8 & 48 & 23 & 56 & $1.26 \mathrm{E}+06$ & 24 & 25 \\
\hline [A11] & 800 & 5 & 48 & 29.5 & 56 & $3.08 \mathrm{E}+05$ & 4 & 102 \\
\hline [A12] & 800 & 6 & 48 & 29.5 & 56 & $5.33 \mathrm{E}+05$ & 8 & 59 \\
\hline [A13] & 800 & 7 & 48 & 29.5 & 56 & $8.46 \mathrm{E}+05$ & 12 & 37 \\
\hline [A14] & 800 & 8 & 48 & 29.5 & 56 & $1.26 \mathrm{E}+06$ & 18 & 25 \\
\hline [A15] & 800 & 9 & 48 & 29.5 & 56 & $1.80 \mathrm{E}+06$ & 26 & 18 \\
\hline [A16] & 800 & 10 & 48 & 29.5 & 56 & $2.47 \mathrm{E}+06$ & 35 & 13 \\
\hline [A17] & 1,500 & 10 & 70 & 19 & 65 & $4.92 \mathrm{E}+06$ & 37 & 6 \\
\hline [A18] & 1,500 & 8 & 66 & 22 & 67 & $2.21 \mathrm{E}+06$ & 17 & 14 \\
\hline [A19] & 1,500 & 10 & 70.5 & 20 & 65 & $4.99 \mathrm{E}+06$ & 38 & 6 \\
\hline [A20] & 1,500 & 8 & 70.5 & 20 & 65 & $2.55 \mathrm{E}+06$ & 19 & 12 \\
\hline [A21] & 1,500 & 8 & 77 & 18 & 100 & $2.53 \mathrm{E}+06$ & 19 & 12 \\
\hline [A22] & 1,500 & 10 & 70 & 19 & 65 & $4.92 \mathrm{E}+06$ & 37 & 6 \\
\hline [A23] & 1,500 & 9 & 70.5 & 20 & 56 & $3.88 \mathrm{E}+06$ & 30 & 8 \\
\hline [A24] & 1,500 & 8 & 70.5 & 20 & 65 & $2.55 \mathrm{E}+06$ & 19 & 12 \\
\hline [A25] & 1,500 & 8 & 77 & 18 & 56 & $3.25 \mathrm{E}+06$ & 25 & 10 \\
\hline [A26] & 1,500 & 8.4 & 77 & 18 & 56 & $3.76 \mathrm{E}+06$ & 29 & 8 \\
\hline [A27] & 1,500 & 10 & 70 & 19 & 65 & $4.92 \mathrm{E}+06$ & 37 & 6 \\
\hline [A28] & 1,500 & 8 & 64 & 17.3 & 80 & $1.93 \mathrm{E}+06$ & 15 & 16 \\
\hline [A29] & 1,500 & 8 & 72 & 17.3 & 64 & $2.68 \mathrm{E}+06$ & 20 & 12 \\
\hline [A30] & 1,500 & 7.7 & 82 & 14.4 & 93.6 & $2.64 \mathrm{E}+06$ & 20 & 12 \\
\hline [A31] & 1,500 & 8.3 & 70 & 19 & 114 & $2.21 \mathrm{E}+06$ & 17 & 14 \\
\hline [A32] & 1,500 & 10 & 70 & 19 & 56 & $5.24 \mathrm{E}+06$ & 40 & 6 \\
\hline [A33] & 1,650 & 8 & 82 & 14.4 & 93.6 & $2.96 \mathrm{E}+06$ & 20 & 11 \\
\hline [A34] & 2,000 & 6 & 71 & 20 & 64 & $1.10 \mathrm{E}+06$ & 6 & 29 \\
\hline [A35] & 2,000 & 8 & 71 & 20 & 64 & $2.61 \mathrm{E}+06$ & 15 & 12 \\
\hline [A36] & 2,000 & 9 & 71 & 20 & 64 & $3.71 \mathrm{E}+06$ & 21 & 8 \\
\hline [A37] & 2,000 & 10 & 71 & 20 & 64 & $5.09 \mathrm{E}+06$ & 29 & 6 \\
\hline [A38] & 2,000 & 6 & 82 & 19 & 85 & $1.30 \mathrm{E}+06$ & 7 & 24 \\
\hline [A39] & 2,000 & 7 & 82 & 19 & 85 & $2.06 \mathrm{E}+06$ & 12 & 15 \\
\hline [A40] & 2,000 & 8 & 82 & 19 & 85 & $3.08 \mathrm{E}+06$ & 18 & 10 \\
\hline [A41] & 2,000 & 7 & 82 & 17.1 & 80 & $2.12 \mathrm{E}+06$ & 12 & 15 \\
\hline [A42] & 2,000 & 7.6 & 92.5 & 15 & 80 & $3.45 \mathrm{E}+06$ & 20 & 9 \\
\hline [A43] & 3,000 & 8 & 104 & 15.3 & 56 & $5.93 \mathrm{E}+06$ & 23 & 5 \\
\hline
\end{tabular}

Note: Local and technical specifications determine the effective electricity produced by each system.

${ }^{a}$ The nominal power indicates maximum power that can be safely converted by the wind turbine.

${ }^{\mathrm{b}}$ The output electricity produced by the wind turbine is calculated based on the engineering equations reported in Caduff and colleagues (2012).

$\mathrm{kW}=$ kilowatts; $\mathrm{m} / \mathrm{s}=$ meters per second; $\mathrm{m}=$ meters; $1 / \mathrm{min}=$ liters per minute; $\mathrm{kWh} / \mathrm{yr}=$ kilowatt-hours per year; $\mathrm{kWh}=\mathrm{kilowatt}$-hours; $\mathrm{s}=$ seconds.

the sound emission (i.e., the turning of the blades). In the LCIA phase, the variation of sound pressure resulting from local conditions is also introduced (see Cucurachi et al. [2012] for more details).

\section{Process Data and Assumptions}

Given the emphasis of the current study on introducing sound emissions and noise impacts in an LCA, the inventory 
data were based on the existing LCI from Caduff and colleagues (2012). We used the modeling principles reported in the main body and supplementary information of Caduff and colleagues (2012) to define the configurations of interest reported in Table 1. The analysis of the use phase of all the 43 configurations of wind turbine was complemented in the current study with their relative sound emissions.

\section{Inventory of Sound Emissions}

In the life cycle of each wind turbine, data availability allowed us to associate sound emissions to the following processes in the life cycle: transportation of components by freight train and lorry; transportation by passenger car for the maintenance of the turbine; excavation of the foundations of the wind turbine; and actual operation of the system.

As recommended by Cucurachi and Heijungs (2014), we collected for each of the relevant sound-emitting phases of the wind turbine life cycle the respective sound power levels. Sound power levels were differentiated where possible in octave bands and expressed in the logarithmic $\mathrm{dB}$ scale. In order to obtain a sound energy in J, the following transformation function was applied (Cucurachi et al. 2012) (equation 1):

$$
m=\left(10^{-12} \times 10^{\frac{\mathrm{Lw}}{10}}\right) \times t
$$

where $m$ represents the sound energy in $\mathrm{J}$ to be inventoried at the LCI stage, $L w$ represents the sound power level in $d B$, and $t$ represents the time in seconds in which a certain process is working for the output under study (thus implicitly for the functional unit) at a specific time of the day and at a specific location. Emissions are recorded at a specific center-frequency band, time of the day, and location. The sound power level $L w$ depends only on the center-frequency band and does not change according to the time of the day and location. The time $t$ is calculated based on the input-output rate of production of the process under study and varies per time of the day and location. The factor $10^{-12}$ has a unit of W.

\section{Transportation}

At different phases during the life cycle of a wind turbine, a variety of basic components need to be transported, for example, from the production site to the assembly site. This study included transportation by freight train, lorry, and passenger vehicle. Sound power levels for each transportation mode were calculated based on Common Noise Assessment Methods in Europe and attributed to the transportation modes used in the study (CNOSSOS-EU; Kephalopoulos et al. 2012).

Transport demands (i.e., the amount of tonne-kilometers per person-kilometers $[\mathrm{tkm} / \mathrm{pkm}]$ of each transport mode per functional unit) from Caduff and colleagues (2012) and ecoinvent were used. The process of transportation of goods has, in the ecoinvent database, the unit of $\mathrm{km}$ or $\mathrm{pkm}$, which represents the transport of 1 tonne of goods/person by a given transport mode over a distance of 1 kilometer $(\mathrm{km})$. For each of the various transport modes, different assumptions and calculations were necessary to associate to a $\mathrm{tkm} / \mathrm{pkm}$ the relative time $t$ necessary to transport a certain good/person for the functional unit under analysis (i.e., $1 \mathrm{kWh}$ ). Details of the calculations are reported in the Supporting Information available on the Journal's website. All the calculated values of sound energy in $\mathrm{J}$ were associated as environmental extensions to the operation of each transportation mode in CMLCA.

\section{Excavation of Foundations}

In the process of excavation of the foundation work for a wind turbine, the time calculated corresponds to the time necessary for a hydraulic digger to excavate the material for the foundation. The process of excavation by hydraulic digger was selected from the ecoinvent database. The sound power level for the hydraulic excavator was defined according to the council directive 2005/88/EC of the European Commission (EC) (EU 2005) and represents the maximum sound power level permitted for excavator loaders. A combined sound energy of $9.064 \times 10^{-01} \mathrm{~J}$ per cubic meter was calculated and associated in CMLCA to the environmental extensions related to the excavation process.

\section{Use Phase of the Wind Turbine}

We selected 43 configurations reported in table 1 . For the configuration of $3,000 \mathrm{~kW}$ (i.e., identified with configuration number 43 in table 1), we assumed similar sound power levels as for the 3,600-kW configuration reported by Zanetta (2008). In order to measure the time necessary for the wind turbine to produce $1 \mathrm{kWh}$, the total produced electricity over the 20 -year lifetime of the wind turbine was calculated for each configuration. Time in seconds per $1 \mathrm{kWh}$ was then obtained, and the respective sound energy per octave-band center frequency was recorded as an environmental extension of each wind turbine during the use phase (see the Supporting Information on the Web). Sound energy values were recorded assuming the installation of the turbine in a rural location and at an unspecified time of the day. The conditions defined in Cucurachi and Heijungs (2014) apply to the archetypes used. Archetypes refer to classes with specific features, thus to representative conditions of frequency of the sound emitted, time of the day of the emission, and location of the emission.

\section{Inventory of Other Elementary Flows}

Other processes in the life cycle were selected from ecoinvent based on the indications in Caduff and colleagues (2012). Calculations are reported in the Supporting Information on the Web. A lifetime of 20 years was assumed also for all components of the wind turbine: nacelle; rotor; tower; foundation; cables; and electronic box. The total electricity produced per year, and per lifetime of the generator, was calculated using standard equations of wind power systems (see Caduff et al. 2012; Table 1, p. 4727). 


\section{Characterization of the Inventory}

The latest update of the CML-IA database of midpoint characterization methods was used (Van Oers 2013). Inventory data were characterized (ISO 2006) using the CML-IA characterization factors. We complemented the CML-IA method with the noise impact assessment method for the quantification of the impacts of noise on humans and characterization factors as provided by Cucurachi and Heijungs (2014). The method provides a list of characterization factors of sound emitted at specific frequency bands, time of the day, and locations. It was not possible to define, at the time of the analysis, a specific country of installation of the wind turbine; therefore, only illustrative locations of emissions (and exposure) were considered. Other inventory items were characterized according to the CML-IA list.

\section{Results}

\section{Analysis of Noise Impacts on Humans}

The noise results after characterization are expressed in units of person $\times$ pascal $\times$ second and indicate, at the midpoint level, the amount of sound pressure each person exposed to a sound power would receive per second, integrated over the full life cycle. The results links, according to the traditional International Organization for Standardization (ISO) 14044 characterization scheme (ISO 2006), the inventory item $m$ specified at the inventory stage with the specific characterization factors defined for different center-frequency bands, times of the day, and locations of emission. The resulting human-noise impacts ranged between 15,000 and 43,900 person $\times$ pascal $\times$ second, respectively the total noise impact values for configuration [A37] and [A41] (see figure 3 below). The lowest score was obtained for the configuration at a nominal power of 2,000 kilowatt-hours $(\mathrm{kW})$, with a wind speed of 10 meters per second $(\mathrm{m} / \mathrm{s})$, a diameter of blades of 71 meters $(\mathrm{m})$, a height of the hub of $64 \mathrm{~m}$, and a total speed of $20 \mathrm{RpM}$. Conversely, the highest score was obtained for the wind turbine with a nominal power of 2,000 kW, a wind speed of $7 \mathrm{~m} / \mathrm{s}$, speed of $17 \mathrm{RpM}$, a height of the hub of $80 \mathrm{~m}$, and a diameter of the wind turbine of $82 \mathrm{~m}$.

The results do not suggest a clear pattern that links the noise impacts to specific values of nominal power, rotational speed, and hub heights. The calculation of the Pearson correlation coefficient did not highlight any strong correlation for the data representing the 43 configurations. A significant negative correlation of -0.5 was found only between the wind speed and the noise impacts, suggesting an increase of noise impacts at lower wind speeds. The wind speed is directly related with the time that the wind turbine needs to obtain a functional unit, thus to obtain $1 \mathrm{kWh}$ of electricity.

The analysis of the relative contributions in the life cycle allows the identification of the most relevant processes in contributing to the noise impacts for each configuration. As shown in figure 3, the share of noise impacts attributable to transportation by freight train ranged between $1 \%$ and $10 \%$ of the total impacts. The impacts determined by transportation by lorry ranged between $4 \%$ and $24 \%$ of the total noise impact. The operation of the wind turbines dominates the remaining of the impact per functional unit (see figure 3 below). The excavation of a foundation and the use of a passenger car for the maintenance of the wind turbines contributed to approximately $1 \%$ of the total noise impacts for all configurations. The combined contribution of transportation determined 34\% of the overall impact for configuration [A11].

During the use phase in the life cycle of a wind turbine, sound is emitted by the functioning of the mechanical components (e.g., yaw motors) and by the aerodynamic flow of air around the blades and tower (Pedersen and Waye 2004). Aerodynamic sound emissions determining a "whooshing" sound are highly variable and dependent upon the technical features of the wind turbine and upon the local atmospheric conditions (e.g., wind speed, RpM). According to the literature, the dominant component is usually in the range of 500 to 1,000 Hertz $(\mathrm{Hz})$ (see Pedersen and Waye 2004). For the case of transportation, emissions in the urban and suburban contexts at around $1,000 \mathrm{~Hz}$ represented the dominant source of impacts. For the operation phase of the wind turbines, frequencies in the range of 500 to $2,000 \mathrm{~Hz}$ were the highest contributors to the total noise impacts for the smaller-sized configurations. At increasing nominal power, frequencies in the lower range of the spectrum $(<500 \mathrm{~Hz})$ contributed the most to the impact, suggesting the prevalence of humming sounds determined by the rotations of the blades. According to Bolin and colleagues (2011) and Møller and Pedersen (2011), the relative amount of low-frequency noise is higher for large turbines than for smaller ones with a prevalence of annoyance and sleep disturbance perceived at or below $250 \mathrm{~Hz}$. In the case of the biggest configuration considered in our analysis, the dominating frequency was $63 \mathrm{~Hz}$ (see the Supporting Information on the Web for a detailed presentation of results).

In all cases, the operation phase contributed to noise impacts at least as much as the transportation-based sources of sound. Although bigger designs have a lower impact per functional unit, the frequency content of the emission highlights an interesting policy outcome. Big turbines are linked to sound emitted at lower frequencies, and such frequencies determine the majority of complaints in areas that are close to human settlements.

In figure 4 below, we take the wind turbine with the biggest nominal power of 3,000 as a reference and compare the resulting noise impacts with other turbines. Impacts are normalized to the reference impact. Four configurations score higher noise impacts than the reference. The results confirm that no clear pattern can be devised by solely looking at the nominal power of the turbine under study; thus, the biggest turbine in the set considered does not necessarily carry the highest impact, as shown by Caduff and colleagues (2012), for other traditional impact categories.

\section{Analysis of Other Impacts}

The results obtained by applying the CML-IA impact categories to the configurations are reported in detail in the 


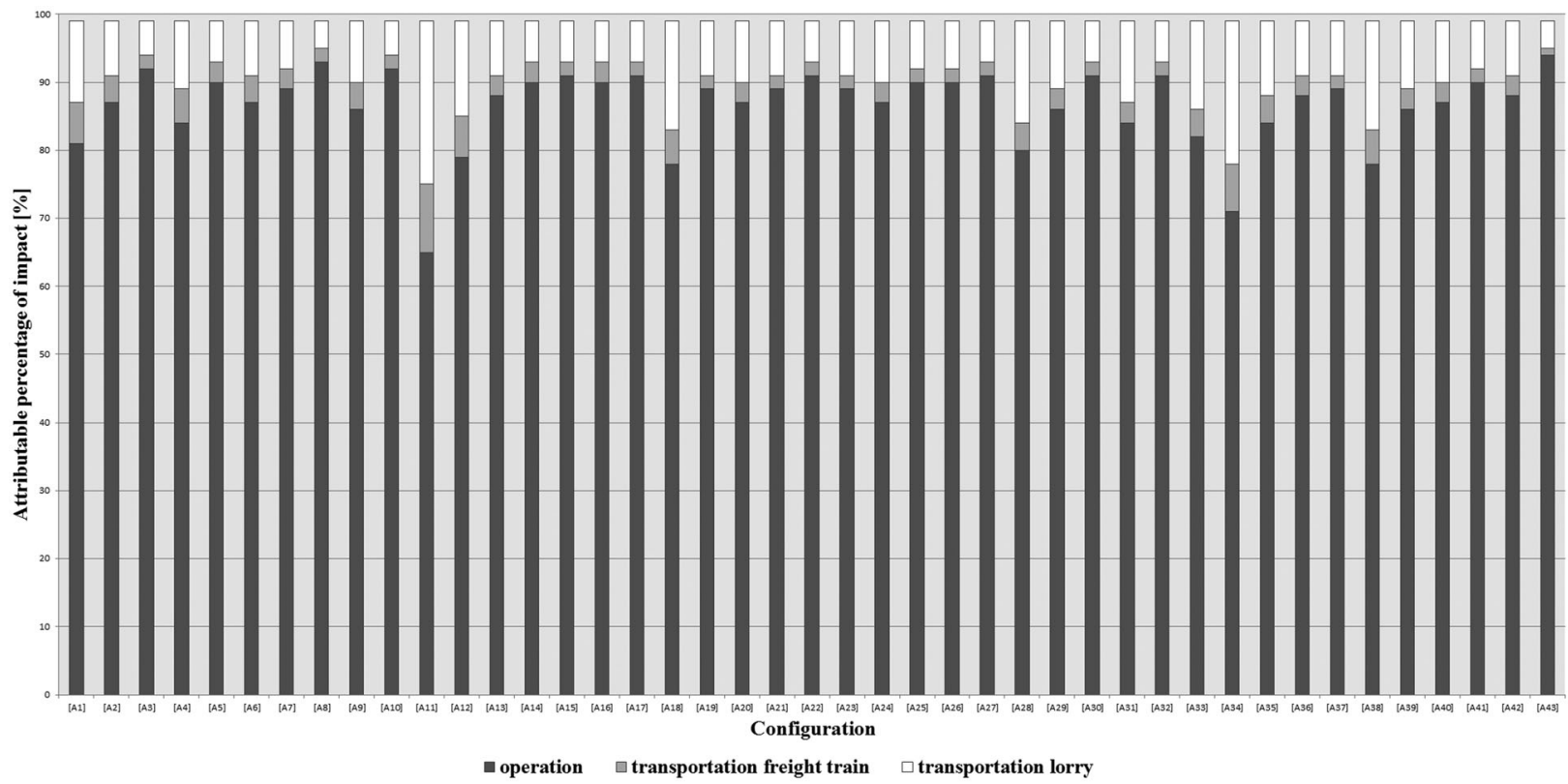

Figure 3 Share of the noise impacts determined by the operation of the wind turbine, by transportation by means of freight train, and transportation by means of lorry. The remaining sound-emitting sources accounted for approximately $1 \%$ of the total and are not reported in the figure.

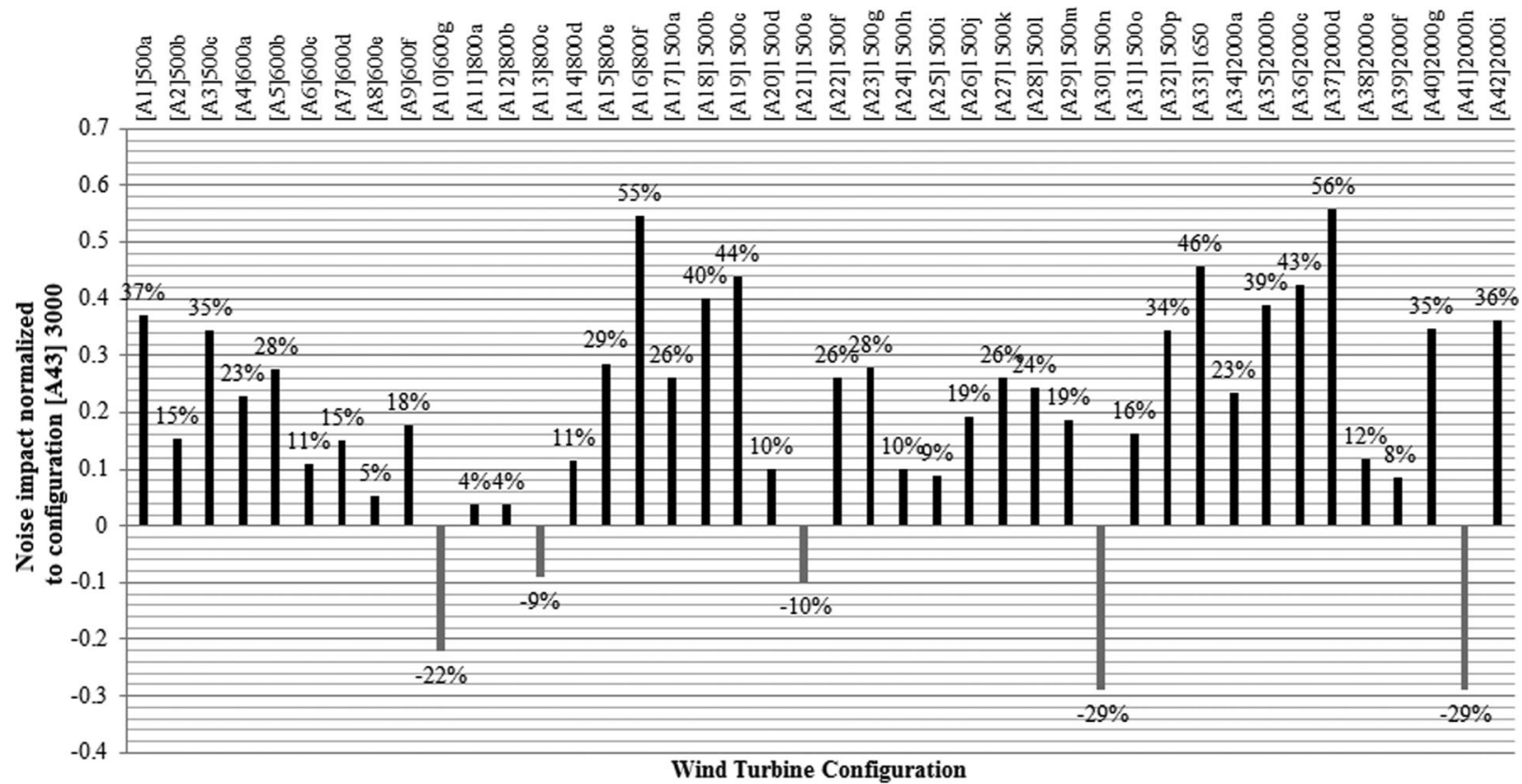

Figure 4 Noise impacts at different configurations compared to the impact score of the wind turbine with a nominal power of 3,000 kW [A43]. Impacts are normalized to the impacts of this configuration. $\mathrm{kW}=$ kilowatts. The values following the configuration names at the top of the graph indicate the nominal power and the subsequent letters indicate the sequential order at similar nominal powers. A negative value indicates that the wind turbine configuration has higher noise impacts than the wind turbine with a nominal power of 3,000 kW.

Supporting Information on the Web and by accessing the project file in CMLCA. We focus here on the performance of a selection of configurations, using one configuration per each class of nominal power. The worst and best performers in terms of noise impacts (i.e., [A37] and [A40]) are also included. Table 2 reports the results for this selection of configurations.
In the selection of CML-IA impact categories reported in table 2, configurations [A37] and [A43] result as best performers (see the Supporting Information on the Web for further details on the other configurations). The worst performer per functional unit is the configuration with a nominal power of $800 \mathrm{~kW}$ [A11]. The local environmental conditions strongly 
Table 2 Selection of CML-IA impacts for a number of configurations

\begin{tabular}{|c|c|c|c|c|c|c|c|c|c|}
\hline $\begin{array}{l}\text { Power [kW] } \\
\text { Configuration }\end{array}$ & $\begin{array}{l}500 \\
{[\mathrm{~A} 1]}\end{array}$ & $\begin{array}{l}600 \\
{[A 8]}\end{array}$ & [A11] & 1,500 & $\begin{array}{l}1,650 \\
{[A 33]}\end{array}$ & $\begin{array}{l}2,000 \\
{[\mathrm{~A} 37]}\end{array}$ & $\begin{array}{l}2,000 \\
\text { [A40] }\end{array}$ & $\begin{array}{l}3,000 \\
{[\mathrm{~A} 43]}\end{array}$ & $\begin{array}{c}\text { Unit } \\
\text { [per KWh] }\end{array}$ \\
\hline \multicolumn{10}{|l|}{ Impact categories } \\
\hline FSET & $1.21 \mathrm{E}-01$ & 5.11E-02 & $2.91 \mathrm{E}-01^{\mathrm{b}}$ & $4.15 \mathrm{E}-02$ & $6.87 \mathrm{E}-02$ & $3.00 \mathrm{E}-02^{\mathrm{a}}$ & $4.96 \mathrm{E}-02$ & $4.65 \mathrm{E}-02$ & $\mathrm{~kg}$ \\
\hline GW20a & 3.37E-02 & $1.67 \mathrm{E}-02$ & $9.88 \mathrm{E}-02$ & $1.22 \mathrm{E}-02$ & $2.02 \mathrm{E}-02$ & $1.15 \mathrm{E}-02$ & $1.89 \mathrm{E}-02$ & $1.08 \mathrm{E}-02$ & $\mathrm{~kg}$ \\
\hline GW100a & $3.01 \mathrm{E}-02$ & $1.50 \mathrm{E}-02$ & 8.87E-02 & $1.09 \mathrm{E}-02$ & $1.81 \mathrm{E}-02$ & $1.03 \mathrm{E}-02$ & $1.69 \mathrm{E}-02$ & $9.74 \mathrm{E}-03$ & $\mathrm{~kg}$ \\
\hline TAE & 7.30E-06 & $5.54 \mathrm{E}-06$ & $2.92 \mathrm{E}-05$ & 3.61E-06 & 5.99E-06 & $3.48 \mathrm{E}-06$ & $5.75 \mathrm{E}-06$ & $2.00 \mathrm{E}-06$ & $\mathrm{~kg}$ \\
\hline MAE & $2.64 \mathrm{E}-02$ & $1.23 \mathrm{E}-02$ & $6.83 \mathrm{E}-02$ & $1.00 \mathrm{E}-02$ & $1.66 \mathrm{E}-02$ & $7.22 \mathrm{E}-03$ & 1.19E-02 & $1.01 \mathrm{E}-02$ & $\mathrm{kBq}$ \\
\hline FAE & $5.21 \mathrm{E}-02$ & $2.28 \mathrm{E}-02$ & $1.29 \mathrm{E}-01$ & $1.87 \mathrm{E}-02$ & $3.11 \mathrm{E}-02$ & $1.34 \mathrm{E}-02$ & $2.22 \mathrm{E}-02$ & 2.00E-02 & $\mathrm{kg}$ \\
\hline OD & E-09 & $1.23 \mathrm{E}-09$ & 6.411 & $7.18 \mathrm{E}-10$ & 1.19E-09 & $6.25 \mathrm{E}-10$ & $1.03 \mathrm{E}-09$ & $5.42 \mathrm{E}-10$ & $\mathrm{~kg}$ \\
\hline HT & $1.54 \mathrm{E}-01$ & 5.92E-02 & $3.21 E-01$ & $4.45 \mathrm{E}-02$ & 7.37E-02 & $3.33 \mathrm{E}-02$ & $5.49 \mathrm{E}-02$ & $6.80 \mathrm{E}-02$ & $\mathrm{~kg}$ \\
\hline $\begin{array}{l}\text { Low NOx PO } \\
\text { (Europe) }\end{array}$ & $9.32 \mathrm{E}-06$ & $3.73 \mathrm{E}-06$ & $2.25 E-05$ & $3.22 \mathrm{E}-06$ & $5.34 \mathrm{E}-06$ & 2.89E-06 & $4.77 \mathrm{E}-06$ & $2.75 \mathrm{E}-06$ & $\mathrm{~kg}$ \\
\hline $\begin{array}{l}\text { High NOx PO } \\
\text { (Europe) }\end{array}$ & $1.04 \mathrm{E}-05$ & 5.35E-06 & $3.05 E-05$ & $4.25 \mathrm{E}-06$ & $7.05 \mathrm{E}-06$ & $3.58 \mathrm{E}-06$ & 5.91E-06 & $3.24 \mathrm{E}-06$ & $\mathrm{~kg}$ \\
\hline $\begin{array}{l}\text { Malodourous air } \\
\text { (global) }\end{array}$ & $5.07 \mathrm{E}+02$ & $2.20 \mathrm{E}+02$ & $1.29 \mathrm{E}+03$ & $1.83 \mathrm{E}+02$ & $3.03 \mathrm{E}+02$ & $1.66 \mathrm{E}+02$ & $2.74 \mathrm{E}+02$ & $1.51 \mathrm{E}+02$ & $\mathrm{~kg}$ \\
\hline $\begin{array}{l}\text { Ionising radiation } \\
\text { (global) }\end{array}$ & $1.05 \mathrm{E}-10$ & $5.67 \mathrm{E}-11$ & $3.15 E-10$ & $3.82 \mathrm{E}-11$ & $6.33 \mathrm{E}-11$ & $3.45 \mathrm{E}-11$ & $5.70 \mathrm{E}-11$ & $3.68 \mathrm{E}-11$ & $\mathrm{~kg}$ \\
\hline $\begin{array}{l}\text { Depletion of abiotic } \\
\text { resources (global) }\end{array}$ & $-2.20 \mathrm{E}-04$ & $-1.10 \mathrm{E}-04$ & $-6.30 \mathrm{E}-04$ & $-7.94 \mathrm{E}-05$ & $-1.30 \mathrm{E}-04$ & $-7.24 \mathrm{E}-05$ & $-1.20 \mathrm{E}-04$ & $-6.83 E-05$ & $\mathrm{~kg}$ \\
\hline
\end{tabular}

Note: See the Supporting Information on the Web for the complete list of results.

a Bold numbers indicate lowest values in the selection.

${ }^{b}$ Italicized numbers indicate highest values in the selection.

$\mathrm{kW}=$ kilowatts; FSET $=$ freshwater sedimental eco-toxicity (measured with the global freshwater sedimental ecotoxicity potential with a time horizon of 20 years); GW20a and GW100a = global warming measured, respectively, with the global warming potential with a time horizon of 20 years and 100 years; TAE = terrestrial eco-toxicity (measured with the global terrestrial eco-toxicity potential with a time horizon of 20 years); FAE $=$ freshwater aquatic eco-toxicity (measured with the global freshwater aquatic eco-toxicity potential with a time horizon of 20 years); OD $=$ ozone layer depletion (measured with the global ozone depletion potential with a time horizon of 20 years); HT = human toxicity (measured with the global human toxicity potential with a time horizon of 20 years); low $\mathrm{NOx} \mathrm{PO}=$ photochemical oxidation low $\mathrm{NOx}$; $\mathrm{MAE}=$ marine aquatic eco-toxicity; $\mathrm{kWh}=\mathrm{kilowatt-hours;} \mathrm{kg}=$ kilograms; $\mathrm{kBq}=$ kilobecquerel.

influence the performance of this wind turbine. The calculated wind speed at hub height is low, corresponding to a low capacity factor. As a result, the impacts per functional unit are, in most cases, an order of magnitude higher than the other configurations. For the case of noise impacts, this configuration performs $10 \%$ better than [A30]. Such a result is owing to the lower sound power level for the corresponding nominal power, local conditions of wind speed, and physical parameters of the turbine. These results are contrary to the widespread view that smaller wind turbines carry higher impacts under all local conditions (i.e., of wind speed, hub height, RpM, and diameter). The score of the contributions to the global warming impact are in line with those found in the review by Arvesen and Hertwich (2012). Values of Pearson correlation around 0.7 were found between noise impacts and the other impacts reported in table 2 .

\section{Concluding Remarks}

We presented a detailed analysis of the case study of wind turbines, which includes, for the first time, the evaluation of the impacts of sound emissions across all phases of the life cycle of a wind turbine. Through the test case of the wind turbine, we have shown in detail how sound emissions may be associated with a variety of processes in a life cycle, from extraction of resources to operation, and how these can be modeled. The selection of the life cycle of a wind turbine allowed assessments of the impacts of an emerging technology, on which a great deal of hope is put in future energy scenarios (see, e.g., Krewitt et al. 2009; SSREN 2011). We show that it is important to also include in the analysis those impacts that are related to the operation phase of the life cycle. Similar conclusions may be drawn for other emerging technologies (e.g., electric cars), which are claimed to have negligible impacts during their use. Some of these impacts will prove to be non-negligible when a suitable method becomes available to quantify them.

The results show that it is now possible to compare the human-related noise performance of systems with a similar functional unit and similar definitions. Variations in local conditions (e.g., wind speed) are important to quantify the noise impact.

For the other impacts considered, the local conditions do not seem to have a strong influence on the entity of the impacts and the conclusion of Caduff and colleagues (2012) holds; thus, 
bigger wind turbines have lower impacts per functional unit (see the review of Arvesen and Hertwich [2012]).

Previous studies of noise in the context of LCA focused on the transportation sector (see, e.g., Althaus et al. 2009a, 2009b). In the current study, we showed that it is possible to associate noise emissions during the operation of the system and also to transportation and excavation in the background system. Such an approach permits the inclusion of the study of noise impacts in LCA in line with other impact categories. Characterization factors for noise impacts quantified in a variety of representative contexts could now be potentially included in LCA databases (e.g., ecoinvent) and regularly used in case studies.

The limits of the currently available LCA studies of wind turbines are amply discussed by Arvesen and Hertwich (2012) and are outside the scope of the current study. We only note that particular attention should be given to the modeling of an accurate capacity factor that best represents the location when the system operates. Selecting too high capacity factors influences the meaning of results. The inventory of the wind turbine configurations was composed using data already available in the study of Caduff and colleagues (2012), and therefore uncertainties and limitations in that research may be assumed for the current study. For the case of sound emissions, the quality of data varied. The availability of a report specifically oriented toward the operation phase of wind turbines allowed for an accurate modeling of sound power levels at specific local conditions, but limited the number of considered configurations to just a set of 43. For other configurations, a case-by-case analysis would be needed. For sound emissions from different transport modes, it was possible to use the CNOSSOS reference report (Kephalopoulos et al. 2012), which also allows for an accurate modeling of sound power levels. For the excavation of the foundations, the data found were not detailed in terms of frequency bands; thus, it was not possible to give this extra nuance in the specification of the characterization of the emission data. The selection of the sound power level as a measure of sound emissions proved to be a reasonable modeling expedient, which simplifies the collection of sound emission data.

From a methodological standpoint, the criteria used for the inventory of sound emissions may serve as a basis for the development of other types of matter-less physical impacts in LCA that, like sound and noise, do not stem from the extraction or release of a $\mathrm{kg}$ of matter. The process of linearization and inventory of sound emissions by means of a time-based factor provides indications on how other physical impacts may be analogously modeled. In order to open up the LCA framework to new impacts that do not have the traditional extraction/emission features, these indications may come handy to approach the modeling phase, especially in the case of matterless emissions and impacts. LCA, however, should not aim to measure all possible impacts, and guidelines should be followed on which impacts to include and to which to give priority (see Cucurachi et al. 2012). For an assessment, especially at a very local level of detail, other decision-support tools in the environmental sciences would be more suitable and would provide less uncertain results.
The ongoing modeling effort to provide LCA with a growing level of spatial detail (see, e.g., Mutel et al. 2011) and temporal detail (Tessum et al. 2012) will certainly help giving the LCA framework the possibility to portray a wide variety of local conditions of emission and exposure. However, this current study shows how difficult it is to model geographical differences when no specific information is available on the location in which certain emissions took place. In principle, the model by Cucurachi and Heijungs (2014) provides spatially explicit characterization factors for the European Union (EU). The use of such factors in the current study was of limited interest because it was not possible to specifically relate emissions to a certain location. In future studies, if extra information on the specific location of a wind turbine is available to the practitioner, those locationspecific characterization factors may be used. However, even then we should check the balance between the added value of a regionalized approach and the added efforts to do the analysis (cf. Heijungs 2012).

\section{Acknowledgments}

The present research was partially funded by the European Commission under the 7th Framework Programme on Environment; ENV.2009.3.3.2.1: LC-IMPACT_Improved Life Cycle Impact Assessment methods (LCIA) for better sustainability assessment of technologies, grant agreement number 243827.

\section{References}

Althaus, H.-J., P. De Haan, and R. W. Scholz. 2009a. Traffic noise in LCA, Part 1: State-of-science and requirement profile for consistent context-sensitive integration of traffic noise in LCA. The International Journal of Life Cycle Assessment 14(6): 560-570.

Althaus, H.-J., P. De Haan, and R. W. Scholz. 2009b. Traffic noise in LCA, Part 2: Analysis of existing methods and proposition of a new framework for consistent, context-sensitive LCI modeling of road transport noise emission. The International Journal of Life Cycle Assessment 14: 676-686.

Arvesen, A. and E. G. Hertwich. 2012. Assessing the life cycle environmental impacts of wind power: A review of present knowledge and research needs. Renewable and Sustainable Energy Reviews 16(8): 5994-6006.

Arvesen, A., C. Birkeland, and E. G. Hertwich. 2013. The importance of ships and spare parts in LCAs of offshore wind power. Environmental Science EO Technology 47(6): 2948-2956.

Blackstock, D. T. 2000. Fundamentals of physical acoustics. John Wiley \& Sons.

Bolin, K., G. Bluhm, G. Eriksson, and M. E. Nilsson. 2011. Infrasound and low frequency noise from wind turbines: Exposure and health effects. Environmental Research Letters 6(3): 035103.

Boccard, N. 2009. Capacity factor of wind power realized values vs. estimates. Energy Policy 37(7): 2679-2688.

Boyle, G. 2004. Renewable energy: Power for a sustainable future. Oxford, UK: Oxford University Press.

Boccard, N. 2010. Economic properties of wind power: A European assessment. Energy Policy 38(7): 3232-3244. 
Brandão, M. and L. Milá i Canals. 2013. Global characterisation factors to assess land use impacts on biotic production. The International Journal of Life Cycle Assessment 18(6): 1243-1252.

Caduff, M., M. A. Huijbregts, H. J. Althaus, A. Koehler, and S. Hellweg. 2012. Wind power electricity: The bigger the turbine, the greener the electricity? Environmental Science $\mathcal{E}$ Technology 46(9): 4725-4733.

Cucurachi, S. and R. Heijungs. 2014. Characterisation factors for life cycle impact assessment of sound emissions. Science of the Total Environment 468-469: 280-291.

Cucurachi, S., R. Heijungs, and K. Ohlau. 2012. Towards a general framework for including noise impacts in LCA. The International Journal of Life Cycle Assessment 17(4): 471-487.

Cucurachi, S., R. Heijungs, W. J. G. M. Peijnenburg, J. F. B. Bolte, and G. R. de Snoo. 2014. A framework for deciding on the inclusion of emerging impacts in life cycle impact assessment. Journal of Cleaner Production 78: 152-163.

Curran, M. A. 2012. Life cycle assessment handbook: A guide for environmentally sustainable products. John Wiley \& Sons.

de Baan, L., R. Alkemade, and T. Koellner. 2013. Land use impacts on biodiversity in LCA: A global approach. The International Journal of Life Cycle Assessment 18(6): 1216-1230.

Doblinger, C. and B. Soppe. 2013. Change-actors in the US electric energy system: The role of environmental groups in utility adoption and diffusion of wind power. Energy Policy 61: 274-284.

Dolan, S. L. and G. A. Heath. 2012. Life cycle greenhouse gas emissions of utility-scale wind power. Journal of Industrial Ecology 16(s1): S136-S154.

EU (European Union). 2005. Directive 2005/88/ec of the European Parliament and of the Council. http://eur-lex.europa.eu/LexUriServ/ LexUriServ.do?uri=OJ:L:2005:344:0044:0046:EN:PDF. Accessed 6 March 2014.

Frischknecht, R., A. Braunschweig, P. Hofstetter, and P. Suter. 2000. Human health damages due to ionising radiation in life cycle impact assessment. Environmental Impact Assessment Review 20(2): 159-189.

Frischknecht, R., N. Jungbluth, H. J. Althaus, G. Doka, R. Dones, T. Heck, and M. Spielmann. 2005. The ecoinvent database: Overview and methodological framework. The International Journal of Life Cycle Assessment 10(1): 3-9.

GWEC (Global Wind Energy Council). 2013. Global wind statistics2012. Brussels: Global Wind Energy Council.

Hanafiah, M. M., R. S. Leuven, N. Sommerwerk, K. Tockner, and M. A. Huijbregts. 2013. Including the introduction of exotic species in life cycle impact assessment: The case of inland shipping. Environmental Science $\mathcal{E}$ Technology 47(24): 13934-13940.

Heijungs, R. 2012. Spatial differentiation, GIS-based regionalization, hyperregionalization, and the boundaries of LCA. In: Environment and energy (pp. 167-175), Milan, Italy: FrancoAngeli.

Heijungs, R. 2013. CMLCA, Chain Management by Life Cycle Assessment. A software tool to support the technical steps of the life cycle assessment procedure (LCA). The software tool with demo files and manual can be downloaded at: www.leidenuniv.nl/cml/ ssp/software/cmlca/index.html\#download. Accessed December $11,2015$.

Heijungs, R. and S. Suh. 2002. The computational structure of life cycle assessment. Vol. 11. New York: Springer Science \& Business Media.

ISO (International Organization for Standardization). 2006. ISO 14044:2006: Environmental management_Life cycle assessment-
Requirements and guidelines. Geneva, Switzerland: International Organization for Standardization.

Kephalopoulos, S., M. Paviotti, and F. Anfosso-Lédée. 2012. Common Noise Assessment Methods in Europe (CNOSSOS-EU). Brussels: Publications Office of the European Union.

Krewitt, W., S. Teske, S. Simon, T. Pregger, W. Graus, E. Blomen, and O. Schäfer. 2009. Energy [R] evolution 2008-A sustainable world energy perspective. Energy Policy 37(12): 57645775 .

Milá i Canals, L. and L. de Baan. 2015. Land Use. In Life Cycle Impact Assessment, pp. 197-222. Dordrecht, the Netherlands: Springer.

Milá i Canals, L. M., G. Rigarlsford, and S. Sim. 2013. Land use impact assessment of margarine. The International Journal of Life Cycle Assessment 18(6): 1265-1277.

Møller, H. and C. S. Pedersen. 2011. Low-frequency noise from large wind turbines. The Journal of the Acoustical Society of America 129(6): 3727-3744.

Mutel, C. L., S. Pfister, and S. Hellweg. 2011. GIS-based regionalized life cycle assessment: How big is small enough? Methodology and case study of electricity generation. Environmental Science $\mathfrak{E}$ Technology 46(2): 1096-1103.

Pedersen, E. and K. P. Waye. 2004. Perception and annoyance due to wind turbine noise- $\mathrm{A}$ dose-response relationship. The Journal of the Acoustical Society of America 116(6): 34603470.

Premalatha, M., T. Abbasi, and S. A. Abbasi. 2014. Wind energy: Increasing deployment, rising environmental concerns. Renewable and Sustainable Energy Reviews 31: 270-288.

Rugani, B., D. Panasiuk, and E. Benetto. 2012. An input-output based framework to evaluate human labour in life cycle assessment. The International Journal of Life Cycle Assessment 17(6): 795812 .

Spielmann, M. and R. Scholz. 2005. Life cycle inventories of transport services: Background data for freight transport. The International Journal of Life Cycle Assessment 10(1): 85-94.

Spielmann, M., C. Bauer, R. Dones, and M. Tuchschmid. 2007. Transport services. e-coinvent report no. 14. Dübendorf, Switzerland: Swiss Center for Life Cycle Inventories.

SSREN. 2011. IPCC special report on renewable energy sources and climate change mitigation. www.uncclearn.org/sites/www.uncclearn.org/ files/inventory/ipcc_summary_for_pm.pdf. Accessed October 12, 2015.

Tessum, C. W., J. D. Marshall, and J. D. Hill. 2012. A spatially and temporally explicit life cycle inventory of air pollutants from gasoline and ethanol in the United States. Environmental Science $\mathbb{E}$ Technology 46(20): 11408-11417.

Udo de Haes, H. A., R. Heijungs, S. Suh, and G. Huppes. 2004. Three strategies to overcome the limitations of life-cycle assessment. Journal of Industrial Ecology 8(3): 19-32.

Van Oers, L. 2013. CML-IA-Database containing characterization factors for life cycle impact assessment. Leiden, the Netherlands: Center of Environmental Science, Leiden University CML. Update April 2013. http://cml.leiden.edu/software/data-cmlia.html. Accessed February 11, 2015.

Vautard, R., F. Thais, I. Tobin, F. M. Bréon, J. G. D. de Lavergne, A. Colette, and P. M. Ruti. 2014. Regional climate model simulations indicate limited climatic impacts by operational and planned European wind farms. Nature Communications 5: Article number 3196. DOI: 10.1038/ncomms4196. 
Verones, F., M. M. Hanafiah, S. Pfister, M. A. Huijbregts, G. J. Pelletier, and A. Koehler. 2010. Characterization factors for thermal pollution in freshwater aquatic environments. Environmental Science $\mathcal{E}$ Technology 44(24): 9364-9369.

Walsh-Thomas, J. M., G. Cervone, P. Agouris, and G. Manca. 2012. Further evidence of impacts of large-scale wind farms on land surface temperature. Renewable and Sustainable Energy Reviews 16(8): 6432-6437.

Zanetta, G. A. 2008. Issues and noise emission data of wind turbines. [In Italian] Piacenza, Italy: CESI Ricerca.

Zhou, L., Y. Tian, S. B. Roy, C. Thorncroft, L. F. Bosart, and Y. Hu. 2012. Impacts of wind farms on land surface temperature. Nature Climate Change 2(7): 539-543.
About the Authors

Stefano Cucurachi is a postdoctoral researcher at the Bren School of Environmental Science \& Management of the University of California Santa Barbara, Santa Barbara, CA, USA. Coen C. van der Giesen is a Ph.D. researcher at the Institute of Environmental Sciences (CML), Leiden University, Leiden, the Netherlands. Reinout Heijungs is an associate professor at the Department of Econometrics and Operations Research, Faculty of Economics and Business Administration, of the VU University, Amsterdam, the Netherlands. Geert R. de Snoo is the dean of the Faculty of Science at Leiden University and professor at the Institute of Environmental Sciences (CML) of Leiden University.

\section{Supporting Information}

Additional Supporting Information may be found in the online version of this article at the publisher's web site:

Supporting Information S1: This supporting information S1 provides additional details regarding the calculation of sound emissions for transportation processes and the excavation of the foundation with a hydraulic digger.

Supporting Information S2: This supporting information S2 provides extensive detail related to the inventory assumptions and the calculations used in this study.

Supporting Information S3: This supporting information S3 consists of a zip file containing (a) an informational page and (b) a CMLCA file that contains the full data set used for the case study. All wind turbine configurations modeled in the study are reported. 